\title{
The Design and Implementation of Equipment Academy Educational Management Information System Based on the Web Environment
}

\author{
Huizhen Xue ${ }^{1,}$, Kuo Yang ${ }^{2, b}$ \\ ${ }^{1}$ Equipment Academy, Beijing 101416, China \\ ${ }^{2}$ School of Automobile, Chang'an University, Xi'an 710064, China \\ axuehuizhen101416@163.com, byangkuochd@qq.com
}

Keywords: Information system; B/S, ASP.NET; Educational management; NET Framework.

\begin{abstract}
In universities, educational administration is a key link in the university management, the quality is directly related to the status of competition in college in contemporary society and even the survival and development. Combined with the actual needs of educational administration, using Microsoft .NET as a development platform to ASP. NET and C \# as the development language, and with the help of Web Form, designing university educational management information system based on B/S structure, and operation of the system to achieve the level of modernization of university educational administration and networking.
\end{abstract}

\section{Introduction}

In recent years,academic management system and university students foster continuous reform and adjustment mechanisms,more diverse forms of teaching.University academic departments work processing and analysis of information on a variety of teaching more onerous and complex, traditional management methods can not meet the needs of the senate higher education management development of the situation and work. Therefore, you must use a computer and network information technology, and explore a modern university teaching management, scientific model.Based on the actual development needs of colleges and universities, proposed building program educational management information system, and related implementation techniques have been described for our discussion [1-2].

\section{Features overview}

Systems for four different users with different design features, namely: School-level management of users, faculty/department level management of users, teacher users, student users. Each corresponding to a different user permissions and the corresponding functions, as shown in Fig.1.

\section{Structural design}

B/S model with a new Web-based technology platform model. The first layer client is a user interface with the entire system, the client application downsized to a common browser software. The second layer of the Web server will start the appropriate process to respond to customer requests and dynamically generate a string of HTML code to embed the results of treatment, returned to the client browser. The third layer of the database server tasks similar to $\mathrm{C} / \mathrm{S}$ mode, is responsible for coordinating the different SQL requests from Web servers, database management.

System from the data flow can be divided into two parts, namely the inflow and outflow data. Judging is the information input/storage and information search/browse from the outside. The following module is class service management, for example, a more detailed description of the system of business processes.

The basic data used in service management courses is that students basic information, basic information about teachers, teachers and students enrollment plan, classroom use of the information, practice teaching information, research project information, academic competitions information, curriculum design information, extracurricular internship information. The other modules are part of 
the information provided by the system administrator or by the student or teacher input, and the other part is to provide an existing database, such as the classroom is to make use of information obtained from the data after timetable another system. With these basic data, the system will be made in accordance with the user's request appropriate treatment, such as the user needs to query curriculum, the only account login first user needs administrator, the user sends a query, the system according to user requests information and user login information from the user to call up the user repository of basic information, such as student number. The use of science to bring up the corresponding numbers timetable information from libraries and library combined enrollment plan, you can get the curriculum needs of users.

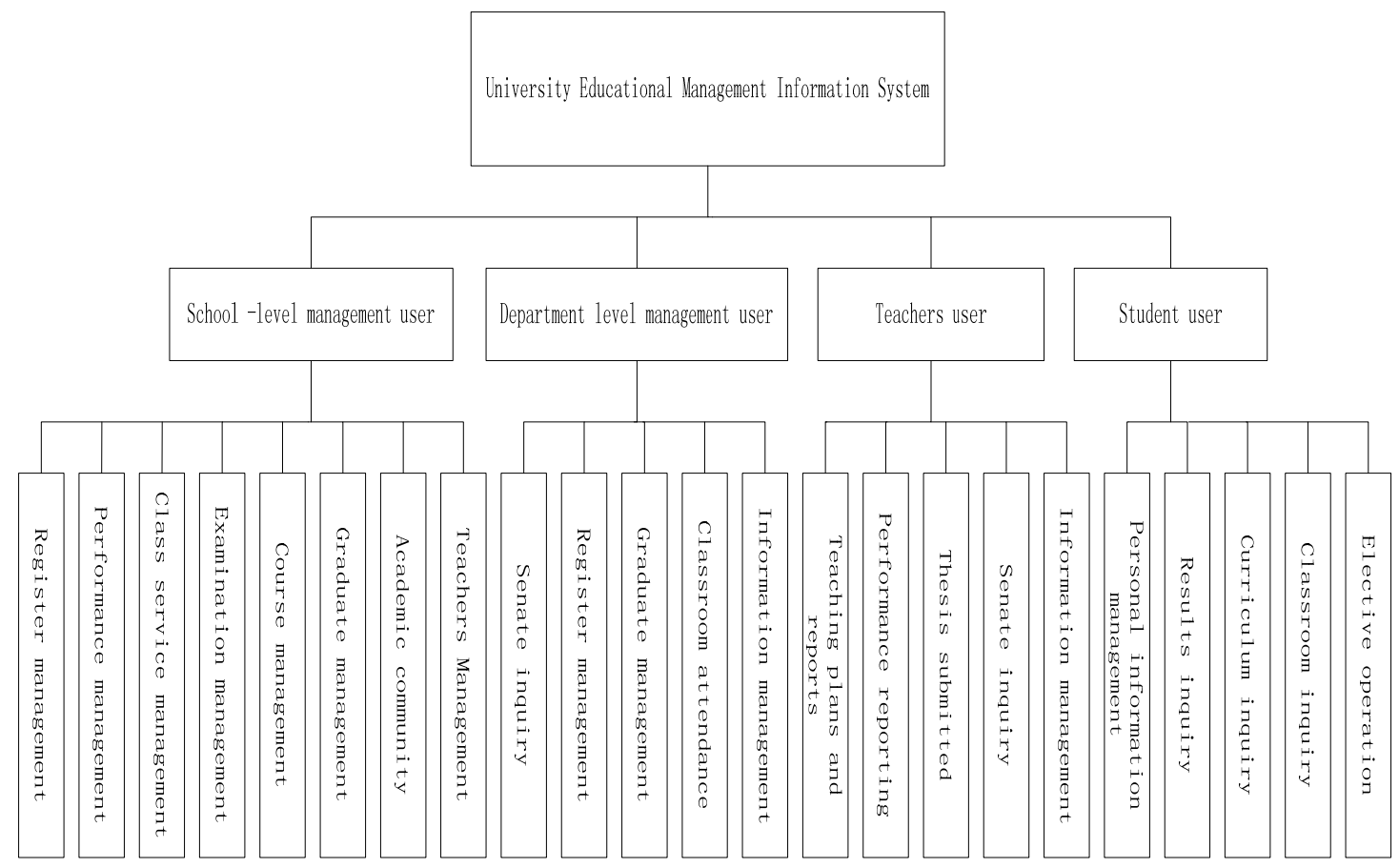

Fig.1 The function of the system

\section{System implementation}

The system will need more data tables, basic database are: teacher information table, teacher attendance sheet, student records table, performance information table, exam schedule, course information table, graduation archive table, practice teaching information table,research project information form, information sheet academic competitions,curriculum design information table, extracurricular internships information table, classrooms record sheet, lesson plans and other information table. Secondary database are: user information table, the system configuration information table, log table, information release form, function menu to store lists. Each table field data type based on the stored data to be, more than the number of bytes to store the data. Construction of the table can easily build these data tables directly using tools provided by SQL Server.

Programming is actually managing and manipulating data, especially information management system. It is the first to solve the problem of database connections, ASP. NET using ADO.NET database connectivity. It provides a platform interoperability and scalable data access. The main purpose is to make it easier to create a distributed data sharing application in the.NET Framework. It provides a data access interface to and OLE DB compliant data sources for communication, such as SQL Server or Oracle.Applications can use ADO.NET to connect these data sources and retrieve, process and update data. Because the data are transmitted in XML format information construction, so any application that can read XML format for data processing programs can be. ADO.NET work flow chart shown in Figure2. 


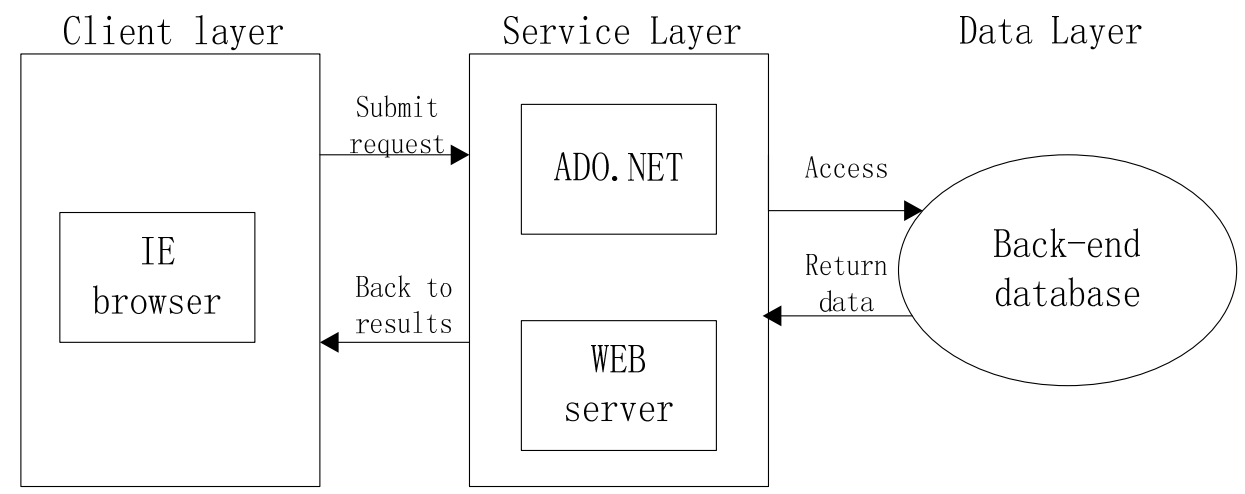

Fig.2 The ADO.NET workflow flowchart

Information System B/S structure is a user-oriented interactive dynamic web site, users of this website to interact with the server.Interactive dynamic web sites and static server program, users with dynamic, interactive website provides a form to fill out the information submitted to the server procedures in order to achieve interoperability purposes.Figure3 is a flow chart of ASP.NET interactive website work.

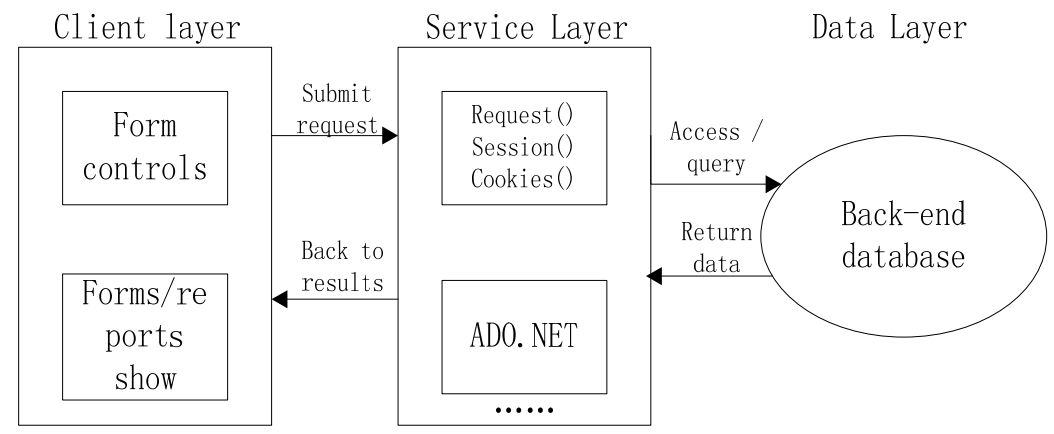

Fig.3 The ASP.NET interactive website work flow chart

Enter information on a form provided by the user in a static site, or user input query, the site will submit the information or the query to the server, the server program will deal with this information. ASP.NET provides a number used to receive and store information page or form submission, these objects include request, session, and cookies and so on. The following code is accepted as a text box to send a student's name and assign it to a session object.

Get the user to submit information, using the above database connection technology, can fill in the information submitted to the database (such as where the student's name), if submitted, for the query, then query the required data from the database through SQL statements. Or get the data from the database to update the database successfully,you should send a page to the website information, there are two commonly used methods, one is the use of session, cookies object storage, because the default session object storage object is valid for 20 minutes.Another is the use of the following in this way, when the steering target page,such as when http://192.168.0.5/teachsys/dataviewer.aspx, we can write the link: http:. //192.168 0.5 / teachsys / dataviewer. aspx? Tsunami = lsstuname. We can also use that page Request object to receive information, received information can be displayed using the form can also be used to display tabular form and can even be displayed in the report. To make the system easier to use, regular use of some special effects scripting language programs, such as JavaScript, VbScript etc.

\section{Conclusion}

NET technology is a new technology,established by the ASP.NET technology is based on B/S university educational management information system architecture greatly simplifies the development process and the difficulty of programming, while B/S structure makes the users do not need to install additional clients will be able to use the system flexible and smooth the university 
administration management processes and computer technology organically combine to make the management process more clear, concise management more flexible, university campus information is indispensable to an important part.

\section{References}

[1] Smith, F. M. (2014). The role of women in educational management and leadership at Ekurhuleni West schools in Tembisa (Doctoral dissertation).

[2] Li, N. (2014). Research on the development of a university educational administration management system. Electrical Engineering and Information Technology, 63, 217.

[3] Hladchenko, M. (2015). Balanced Scorecard-a strategic management system of the higher education institution. International Journal of Educational Management, 29(2).

[4] Sallis, E. (2014). Total quality management in education. Routledge.

[5] Rongge, M. D. L. (2002). A Three-tier Design Model for ASP. Net-based Web Applications [J]. Microcomputth Applications, 3, 007.

[6] Team, W. A., Loesgen, B., Eide, A., Clark, M., Miller, C., Reynolds, M., \& Lee, D. (2001). Professional ASP. NET web services. Word Press Ltd.

[7] Zhen-Jun, F. A. N. (2007). Implementation Method of ASP. Net-based the Three Layers [J]. Computer Science, 4, 080.

[8] Scott-Ladd, B., \& Chan, C. C. (2008). Using action research to teach students to manage team learning and improve teamwork satisfaction. Active Learning in Higher Education, 9(3), 231248. 